\title{
Clofarabine-phytochemical combination exposures in CML cells inhibit DNA methylation machinery, upregulate tumor suppressor genes and promote caspase-dependent apoptosis
}

\author{
AGNIESZKA KAUFMAN-SZYMCZYK ${ }^{1}$, KATARZYNA MAJDA ${ }^{1}$, AGATA SZUŁAWSKA-MROCZEK ${ }^{1}$, \\ KRYSTYNA FABIANOWSKA-MAJEWSKA ${ }^{2}$ and KATARZYNA LUBECKA ${ }^{1}$ \\ ${ }^{1}$ Department of Biomedical Chemistry, Faculty of Health Sciences, Medical University of Lodz, 92-215 Lodz; \\ ${ }^{2}$ Faculty of Medicine, Lazarski University, 02-662 Warsaw, Poland
}

Received March 15, 2019; Accepted July 2, 2019

DOI: $10.3892 / \mathrm{mmr} .2019 .10619$

\begin{abstract}
Clofarabine (2-chloro-2'-fluoro-2'-deoxyarabinosyladenine, CIF), a second-generation 2'-deoxyadenosine analog, possesses a variety of anti-cancer activities, including the capacity to modulate DNA methylation marks. Bioactive nutrients, including resveratrol (RSV) and all-trans retinoic acid (ATRA) have been indicated to regulate epigenetic machinery in malignant cells. The purpose of the current study was to evaluate whether the tested phytochemicals, RSV or ATRA, can improve the therapeutic epigenetic effects of CIF in chronic myeloid leukemia (CML) cells. The present study investigates, to the best of our knowledge, for the first time, the influence of CIF in combination with RSV or ATRA on the expression of relevant modifiers of DNA methylation machinery, including DNA Methyltransferase 1 (DNMT1) and Cyclin dependent kinase inhibitor 1A (CDKN1A) in CML cells. Subsequently, the combinatorial effects on promoter methylation and transcript levels of methylation-silenced tumor suppressor genes (TSGs), including phosphatase and tensin homologue (PTEN) and retinoic acid receptor beta $(R A R B)$, were estimated using MSRA and qPCR, respectively. The tested TSGs were chosen according to bioinformatical analysis of publicly available clinical data of human DNA methylation and gene expression arrays in leukemia patients. The K562 cell line was used as an experimental CML in vitro model. Following a period of $72 \mathrm{~h}$ exposure of K562 cells, the tested combinations led to significant cell growth inhibition and induction of caspase-3-dependent apoptosis. These observations were accompanied by DNMT1 downregulation and $C D K N 1 A$ upregulation, with a concomitant enhanced decrease
\end{abstract}

Correspondence to: Dr Katarzyna Lubecka, Department of Biomedical Chemistry, Faculty of Health Sciences, Medical University of Lodz, 6/8 Mazowiecka, 92-215 Lodz, Poland

E-mail: katarzyna.lubecka-pietruszewska@umed.lodz.pl

Key words: clofarabine, phytochemicals, DNA methylation, tumor suppressor genes, chronic myeloid leukemia in DNMT1 protein level, especially after ATRA treatment with CIF. Concurrent methylation-mediated RARB and PTEN reactivation was detected. The results of the current study demonstrated that CIF that was used in combination with the tested phytochemicals, RSV or ATRA, exhibited a greater ability to remodel DNA methylation marks and promote cell death in CML cells. These results may support the application of CIF combinations with natural bioactive agents in anti-leukemic epigenetic therapy.

\section{Introduction}

Chronic myeloid leukemia (CML) is a myeloproliferative disorder characterized, in the vast majority of cases, by the presence of Philadelphia chromosome $(\mathrm{Ph})$ formed by translocation of sections between chromosomes 9 and 22. Abnormally short chromosome 22 encodes the chimeric p210 BCR-ABL tyrosine kinase protein, a product of the oncogene $B C R-A B L$, constitutively active enzyme that drives uncontrolled cellular growth and differentiation of CML cells. The Ph chromosome with the $B C R-A B L$ fusion gene is also present in $25-50 \%$ of adult patients with acute lymphoblastic leukemia (ALL) and rare cases of acute myeloid leukemia (AML) $(1,2)$.

$\mathrm{BCR}-\mathrm{ABL}$ is the target of tyrosine kinase inhibitors (TKIs) introduced, with great success, for the treatment of CML patients at the end of the last century. Despite the high therapeutic efficacy of TKIs, around 25\% of CML patients develop resistance to 1st (Imatinib) and 2nd (Desatinib, Nilotinib) line of TKIs. This resistance may result from mutations within the kinase domain of BCL-ABL, although other mechanisms of primary or acquired resistance to TKIs have been investigated as well (2-5). Apart from these genetic abnormalities also epigenetic alterations may contribute to CML pathogenesis and drug resistance $(6,7)$. TKIs effectively inhibit BCR-ABL kinase, although CML stem cell survival has been observed (5). Thus, it is reasonable to seek a novel epigenetic approach to improve CML treatment.

Epigenetic alterations regulate gene expression via DNA methylation, histone modifications and activity of non-coding RNAs $(8,9)$. Interference between these epigenetic processes affects chromatin accessibility for transcription (8). Although, 
it is still DNA methylation that is the most stable epigenetic reaction modulating gene expression. It consists of the attachment of methyl group to cytosine mainly in $\mathrm{CpG}$ islands within gene promoters. Dysregulated epigenetic code, including aberrant methylation patterns, is often observed and considered to be one of the causes, in addition to genetic changes, of the development and progression of neoplastic diseases $(10,11)$. In cancer cells, a certain pool of genes (mainly tumor suppressor genes) is silenced by methylation of their promoter regions while other genes are activated (oncogenes and prometastatic genes) through the hypomethylation of their regulatory regions. Methylation patterns of DNA are controlled by enzymes named DNA methyltransferases (DNMTs). DNMTs family include methyltransferases DNMT3a and DNMT3b responsible for the de novo methylation and the major DNMT1 which maintains and ensures the fidelity of replication of inherited epigenetic marks and shows a preference for hemi-methylated DNA (12).

As we have shown in our previous studies deoxyadenosine analog-clofarabine (2-chloro-2'-fluoro-2'-deoxyarabinosyladenine, CIF), apart from its anticancer activity resulting from inhibition of ribonucleotide reductase and DNA polymerases, and apoptosis induction by altering mitochondrial activity, can also modulate gene expression via redesigning DNA methylation patterns within gene regulatory regions in cancer cells $(13,14)$. All these molecular mechanisms of CIF anticancer action contributed to the FDA-approved therapeutic usage of this drug in ALL and some AML cases $(15,16)$.

Natural phytochemicals have raised considerable interest not only as chemopreventive agents but also as chemotherapeutic adjuvants because of their anticancer properties demonstrated in a large number of studies (17). Resveratrol (3,4',5-trihydroxystilbene, RSV), the polyphenol from red grapes and peanuts, has been shown to modulate cell cycle, survival and apoptosis also through altering gene methylation patterns (18-22). Other possible molecular targets of RSV are AMPK and SIRT1, mTOR, NF-kB, PI3K/AKT, MAPK signaling pathways (23).

ATRA (all-trans retinoic acid) is a natural, physiologically active, predominant metabolite of vitamin A. ATRA acts as a hormone and impacts many physiological processes. ATRA through its binding to specific nuclear retinoic acid receptors RARs (RARA, RARB and RARG) that form heterodimers with retinoid $X$ receptors $\mathrm{RXRs}$ can regulate transcription of some genes (24). Within promoters of these genes, the retinoic acid response elements (RAREs) have been found. According to present knowledge, the transcriptional activity of RAR/RXR complex results from the incorporation of ATRA to RAR receptors. This model of interaction is known as a classical or genomic pathway that regulates cell differentiation, cell cycle, and apoptosis (25). RARs and RXRs are able to create heterodimers with other receptors, such as vitamin D receptor (VDR), steroid receptors or peroxisome proliferator-activated receptor (PPAR). There is evidence that ATRA can also regulate the gene expression independently of the presence of RAREs. Furthermore, ATRA and its receptors may affect other critical signaling pathways, including $\mathrm{NF}-\kappa \mathrm{B}$, IFN-G, TGFB, VEGF, and MAPK pathways, as well as cause chromatin remodeling $(24,26)$. Because of ATRA importance in cell physiology, the antitumor activity of retinoids has been broadly studied. Consequently, ATRA heretofore has gained
FDA approval for treatment of APL (acute promyelocytic leukemia) and cutaneous T-cell lymphoma. There are some suggestions that the cause of the lack of ATRA anticancer activity in other types of leukemia and solid tumors might be associated with aberrant epigenetic marks, for example, frequent DNA methylation-mediated silencing of retinoic acid receptor beta $(R A R B)(26,27)$.

Interestingly, the growing body of literature demonstrates that some natural bioactive compounds, including ATRA and RSV, might be indirectly involved in the regulation of DNMT1 expression and/or DNMT1 activity. DNMT1 has been shown to be overexpressed in many types of cancer (28). The following mechanisms responsible for ATRA or RSV-mediated DNMT1 downregulation in cancer cells have been detected, i.e., cyclin-dependent kinase inhibitor $1 \mathrm{~A}(C D K N 1 A)$ transcriptional reactivation $(18,29)$ followed by decreased activity of E2F (elongation factor 2) transcription factor, as well as re-expression of DNA methylation-silenced tumor suppressor genes, phosphatase and tensin homologue (PTEN) and RARB, encoding proteins that may inhibit activity of AP-1 (activator protein-1) transcriptional complex $(29,30)$. E2F and AP-1 transcription factors activate DNMT1 expression due to the presence of binding sites in DNMT1 regulatory region $(31,32)$.

Moreover, CDKN1A ( $p 21$ ) belongs to tumor suppressor genes and encodes a protein that competes with DNMT1 for the same binding site on proliferating cell nuclear antigen (PCNA, the homotrimeric ring surrounding DNA) during DNA replication. It disrupts the forming of DNMT1/PCNA complex and subsequently may lead to inhibition of DNA methylation reaction $(33,34)$. PTEN was shown to be mutated or DNA methylation-silenced in a large number of malignancies. PTEN protein as a phosphatase negatively regulates intracellular levels of phosphatidylinositol-3,4,5-trisphosphate in cells which is crucial for its tumor suppressive activity. The dephosphorylated phosphoinositide through negative regulation of PI3K/AKT and MAPK/AP-1 signaling pathways modulates cell cycle progression and cell survival (35).

The promising results of combining nucleoside analogues, such as cladribine and fludarabine (CIF precursors), with ATRA or RSV in breast cancer cells, including methylation-mediated $P T E N$ and $R A R B$ transcriptional reactivation $(18,30)$, indicate that the combination of CIF with these phytochemicals (ATRA or RSV) may exhibit a new effective approach in anticancer epigenetic therapy.

As mentioned above, alterations in DNA methylation marks are common in cancer cells, including different leukemia cells. Thus, the present study aimed to evaluate anticancer potential of CIF combined with natural bioactive compounds, RSV or ATRA, in K562 cells representing an experimental in vitro model of CML cells. This is the first study to investigate the influence of CIF-phytochemical combination exposures on the regulation of DNA methylation machinery in CML cells. We focused on determining any changes in DNMT1 and CDKN1A expression, as well as in promoter methylation and expression of tumor suppressor genes PTEN and RARB.

\section{Materials and methods}

Compounds and chemicals. All tested compounds CIF, ATRA, and RSV were purchased from Sigma-Aldrich. CIF 
was dissolved in sterile water $(1 \mathrm{mM})$ and stored in $-20^{\circ} \mathrm{C}$. Solutions of ATRA (10 mM) and RSV (5 mM) were prepared in $96 \%$ ethanol and stored in the dark in $-20^{\circ} \mathrm{C}$. Subsequent dilutions were made in growth fresh medium with a final ethanol concentration of $0.1 \%(\mathrm{v} / \mathrm{v})$, and this ethanol concentration was used as vehicle control in all experiments.

Cell culture, growth and viability assay. Human erythroleukemic cell line K562 (American Type Culture Collection, ATCC) was cultured in RPMI 1640 medium with HEPES (Lonza) supplemented with $2 \mathrm{mM}$ L-glutamine, $10 \%$ foetal bovine serum (FBS), $1 \mathrm{U} / \mathrm{ml}$ penicillin and $1 \mu \mathrm{g} / \mathrm{ml}$ streptomycin (Sigma-Aldrich), at $37^{\circ} \mathrm{C}$ and a humidified atmosphere of $5 \% \mathrm{CO}_{2}$. K562 cell line was routinely verified by morphology, invasion and growth rate. The tested cell line was authenticated by DNA profiling using the short tandem repeat (ATCC), in 2018. In all experiments the cells were seeded at the amount of $40 \times 10^{3}$ cells per $\mathrm{ml}$, and were cultured for $72 \mathrm{~h}$ with three different compounds, CIF, ATRA and RSV, used separately, at concentrations equal to $\mathrm{GI}_{50}$ concentrations (i.e., doses leading to $50 \%$ inhibition of cell growth), respectively: $8 \mathrm{nM}$ (CIF), $30 \mu \mathrm{M}$ (ATRA) and $11.5 \mu \mathrm{M}$ (RSV). Additionally, the cells were treated for $72 \mathrm{~h}$ with the compounds administered in two combinations: CIF + ATRA (both at $\mathrm{GI}_{50}$ concentrations, i.e., $8 \mathrm{nM}$ for CIF and $30 \mu \mathrm{M}$ for ATRA) and CIF + RSV (both at $\mathrm{GI}_{50}$ concentrations, i.e., $8 \mathrm{nM}$ for CIF and $11.5 \mu \mathrm{M}$ for RSV).

Cell growth and viability were determined using the trypan blue (Sigma-Aldrich) exclusion test, to estimate $\mathrm{GI}_{50}$ values The number of viable cells in culture treated with the tested compounds was expressed as a percentage of viable cells in control untreated culture (without the compounds, vehicle control). The following calculation has been used: (viable exposed/viable vehicle control)*100\%. The number of dead cells that took up trypan blue was specified as the percentage of the total cell number.

The number of viable, necrotic, early and late apoptotic cells were determined after $72 \mathrm{~h}$ compound exposure by flow cytometry analysis using annexin V/propidium iodide (PI) (FITC Annexin V Apoptosis Detection Kit II, BD Pharmingen) staining, according to the manufacturer's protocol (13). The following excitation/emission wavelengths have been used: FITC 488/519 nm and PI 488/617. Caspase-3 assay (PE Active Caspase-3 Apoptosis Kit, BD Pharmingen) was performed to estimate its activity as a marker of the early stage of the caspase-dependent apoptotic pathway. The excitation/emission wavelengths of 488/578 $\mathrm{nm}$ have been applied. The flow cytometry analysis was carried out using BD FACSuite ${ }^{\mathrm{TM}}$ version 1.2.1 software.

Methylation-sensitive restriction analysis (MSRA). The methylation level of the proximal promoter of PTEN and $R A R B$ in K562 cells was estimated using methylation-sensitive restriction analysis according to the method of Iwase et al (36). The MSRA included four steps: i) digestion of cellular DNA with endonuclease that recognizes only non-methylated sequence, ii) PCR amplification of digested DNA with PCR primers shown in Table I, iii) electrophoretic analysis of amplified promoter fragments, and iv) densitometric quantitative analysis of the band intensity. The analysis was performed as described previously (13).
Reverse transcription quantitative $(R T-q) P C R$. Total RNA was isolated using TRIZOL ${ }^{\circledR}$ (Invitrogen, USA). cDNA was synthesized using $2 \mu \mathrm{g}$ of total RNA, $6 \mu \mathrm{l}$ of random hexamers, $5 \mu \mathrm{l}$ of oligo $(\mathrm{dT})_{15}$, and ImProm-II reverse transcriptase (Promega, USA). All RT-qPCR reactions were carried out in a Rotor-Gene TG-3000 machine (Corbett Research, Australia) as we previously described $(13,14)$. RPS17 $(40 \mathrm{~S}$ ribosomal protein S17), RPLPO (60S acidic ribosomal protein P0), H3F3A (H3 histone family $3 \mathrm{~A})$, and $B M G$ ( $\beta_{2}$-microglobulin) were used as housekeeping control genes. The relative expression of each tested gene (DNMT1, CDKN1A, PTEN, and RARB) was normalized to the geometric mean of these four housekeeping genes, according to the method of Pfaffl et al (37). Primers sequences for RT-qPCR are shown in Table II.

Measuring the amount of DNMT1 protein. Protein nuclear extracts were isolated using the EpiQuik Nuclear Extraction Kit (Epigentek), according to manufacturer's protocol. The ELISA-like EpiQuik DNMT1 Assay Kit (Epigentek) was used for quantification of DNMT1 (DNA methyltransferase) in $10 \mu \mathrm{g}$ of the total protein content. Each measurement was performed in triplicates according to the instructions in the manual. The absorbance at $450 \mathrm{~nm}$ was measured on a microplate reader (GloMax-Multi+ Microplate Multimode Reader, Promega) within 2-10 min.

Statistical analysis. Results from three independent experiments are presented as the mean \pm standard deviation (SD). Statistical analysis of cell viability, apoptosis, MSRA, qPCR and ELISA-like EpiQuik DNMT1 assays was performed using two-way analysis of variance (ANOVA) followed by Bonferroni post hoc test. The results were considered statistically significant when $\mathrm{P}<0.05$.

\section{Results and Discussion}

Effects of RSV and ATRA combined with CIF on inhibition of CML cell growth and apoptosis induction. Following 72 h-exposure, all the tested compounds used alone, CIF, RSV, and ATRA, inhibited K562 cell growth in a dose-dependent manner with low cytotoxicity (Fig. 1A-C and F). The trypan blue exclusion test was carried out to determine concentrations leading to $50 \%$ inhibition of cell growth $\left(\mathrm{GI}_{50}\right)$ (Fig. 1A-C). The $\mathrm{GI}_{50}$ concentration for CIF was determined as equal to $8 \mathrm{nM}$ in K562 cells (Fig. 1A), as we showed previously (13). $\mathrm{GI}_{50}$ values for RSV and ATRA were determined as equal to 11.5 and $30 \mu \mathrm{M}$, respectively (Fig. $1 \mathrm{~B}$ and $\mathrm{C}$ ). The number of dead cells upon exposure to the tested compounds at $\mathrm{GI}_{50}$ concentrations did not exceed $10 \%$ (Fig. 1A-C), which support the use of all the compounds at $\mathrm{GI}_{50}$ concentrations in the combinatorial administrations, CIF and RSV, or CIF and ATRA (Fig. 1D-F).

Next, the cytotoxicity of all the compounds administered individually and in combinations was determined by employing flow cytometric assay (Fig. 2). The number of necrotic (Ann-/PI+) cells did not exceed $10 \%$ of all the cells upon any of the exposures, supporting low cytotoxicity of the tested concentrations (Fig. 2B, top and bottom panels). The use of CIF+RSV combination resulted in the most severe induction of apoptosis in K562 cells (Fig. 2C, upper panel). The 
Table I. PCR primer sequences.

\begin{tabular}{lllc}
\hline Gene & Forward primer (5'-3') & Reverse primer (5'-3') & Product (bp) \\
\hline PTEN & gcggaagcagccgttcggag & gtcatgtctgggagcctgtg & 286 \\
RARB & ctcgctgcctgcctctctgg & gcgttctcggcatcccagtc & 295 \\
\hline
\end{tabular}

Table II. SYBR-Green-based reverse transcription-quantitative PCR primer sequences.

\begin{tabular}{llll}
\hline Gene & Forward primer (5'-3') & \multicolumn{1}{c}{ Reverse primer (5'-3') } & Product (bp) \\
\hline DNMT1 & accgccectggccaaagccattg & agcagcttcctcctcctttatttagctgag & 100 \\
CDKN1A & gctcaggggagcaggctgaag & cggcgtttggagtggtagaaatctgt & 103 \\
PTEN & cgaactggtgtaatgatatgt & catgaacttgtcttccegt & 330 \\
RARB & ttcaagcaagcctcacatgtttcca & aggtaattacacgctctgcacctttag & 292 \\
\hline
\end{tabular}

number of apoptotic cells increases from nearly $4 \%$ after CIF alone and $10 \%$ after RSV alone to $15 \%$ after combined administration CIF+RSV (Fig. 2C, upper panel). This enhanced pro-apoptotic effect of combinatorial CIF and RSV was associated with caspase-3 activation (Fig. 2D, upper panel). Upon $72 \mathrm{~h}$-incubation with this combination over $9 \%$ of all K562 cells showed active caspase 3, whereas after CIF or RSV alone approximately $2 \%$ or $5.5 \%$ of all K562 bound antibodies against caspase 3 , respectively (Fig. 2D, upper panel). The extent of the effects of ATRA alone and CIF+ATRA on cell viability and caspase-dependent apoptosis was not as robust as for RSV used alone or in combination with CIF (Fig. 2C, bottom panel). The number of apoptotic cells increases from 4-5\% after CIF or ATRA used alone to slightly more than $6 \%$ after combined administration, CIF+ATRA (Fig. 2C, bottom panel). The percentage of K562 cells with active caspase-3 was similar after the individual (2-3\%, CIF or ATRA) and combinatorial (3.5\%, CIF+ATRA) exposures (Fig. 2D, bottom panel).

Hitherto, only Lee and colleagues demonstrated that RSV in combination with CIF induces relevant anti-proliferative effects in malignant mesothelioma MSTO-211H and H-2452 cells. This observation was linked to multi-targeted anticancer effects, including inhibition of AKT activity $(20,21)$.

Sui et al (38) showed that RSV indicates significant cytotoxic effect and induces apoptosis in K562 cells in a dose and time-dependent manner. The authors suggested that downregulation of the PI3K/AKT/mTOR signaling cascades (through the attenuated phosphorylation) may be a crucial mediator in the inhibition of proliferation and induction of apoptosis by resveratrol in K562 cells.

Results of Wang et al (39) also indicated that resveratrol significantly decreases cell viability and triggers cell apoptosis in K562 cells. They observed up-regulation of Bax/Bcl-2 ratio, the activation of caspase- 3 and increased PARP cleavage in K562 cells treated with resveratrol (39).

Interdependence between DNMT1 and CDKN1A expression upon combinatorial exposures in K562 cells. Aberrant methylation pattern is a common feature of cancer cells. The purpose of the study was to investigate the interdependence between DNA methylation and expression of selected tumor suppressor genes and the expression of the main DNA methyltransferase, DNMT1, after treatment of model CML cells with a chemotherapeutic agent, CIF, combined with natural bioactive compounds, RSV and ATRA.

First of all, we analyzed the publicly available data from Oncomine for DNMT1 expression in different types of leukemia, as DNMT1 overexpression has been observed in many types of cancer (28). As depicted in Fig. 3A, in almost all types of leukemia DNMT1 expression is significantly higher compared to healthy individuals. Only in CML, the level of DNMT1 expression is lower than in normal blood cells, although the only available microarray data of CML, presented in Fig. 3A, are not statistically significant, so it is difficult to draw clear conclusions about the level of DNMT1 in CML cells. However, Mizuno et al (40) reported relevant DNMT1 up-regulation in AML and CML cells as compared to normal blood cells.

In our study, in K562 cells treated with CIF at $\mathrm{GI}_{50}$ concentration $(8 \mathrm{nM})$ for $72 \mathrm{~h}$, slight almost $10 \%$ reduction in DNMT1 gene expression, in comparison to control unexposed cells, was estimated using RT-qPCR and Pfaffl's method (37) (Fig. 3D). The effects of exposure to RSV or ATRA administered alone, also at $\mathrm{GI}_{50}$ concentrations, caused an even greater diminution in DNMT1 mRNA levels by 15 and $35 \%$, respectively. However, the most robust, over $40 \%$ decrease in DNMT1 expression was noticed as the effect of combined exposure to CIF and ATRA (Fig. 3D, bottom panel). These changes in the expression of DNMT1 at the mRNA level correspond to changes in gene expression at the protein level, determined using ELISA-like commercial immunoassays (Fig. 3C). The combination CIF+ATRA caused almost 50\% reduction in DNMT1 protein level as compared to control K562 cells (Fig. 3C, bottom panel). CIF and ATRA used alone led only to 11 and $29 \%$ decrease in DNMT1 protein levels, respectively (Fig. 3C). It has been shown that manifestation of the catalytic function of DNMT1 enzyme requires its binding to PCNA during DNA replication $(33,34)$. Moreover, CDKN1A, as an antagonist of DNMT1, binds to the same 

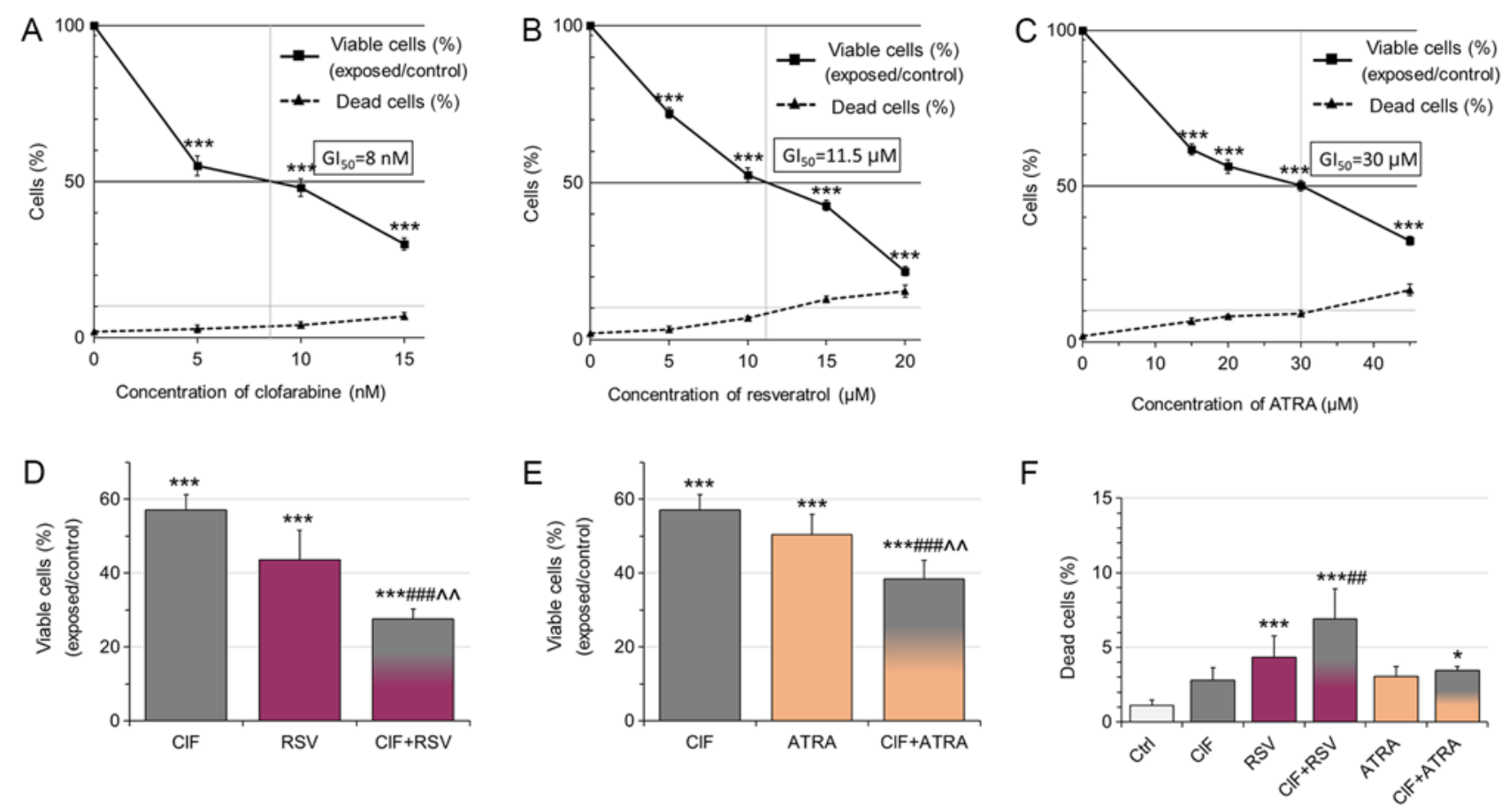

Figure 1. Effects of (A) CIF, (B) RSV and (C) ATRA on K562 cell growth and viability. Data represent the mean \pm standard deviation of three independent experiments. The number of viable cells after 3 days exposure to CIF, RSV and ATRA at GI ${ }_{50}$ concentrations was expressed as a percentage of viable cells in the vehicle control [(viable exposed/viable vehicle control)* $100 \%$ ]. $\mathrm{GI}_{50}$ values were determined as equal to: $8 \mathrm{nM}$ for CIF, $11.5 \mu \mathrm{M}$ for RSV, and $30 \mu \mathrm{M}$ for ATRA. The number of dead cells in either vehicle control or exposed group was calculated as a percentage of the total cell number [(dead cells/all cells)* $100 \%]$. Effects of (D) CIF, RSV and CIF+RSV, as well as (E) CIF, ATRA and CIF+ATRA at GI ${ }_{50}$ concentrations on K-562 cell viability [(viable exposed/viable vehicle control) $x$ 100\%]. (F) The number of dead cells in either vehicle control or exposed groups was calculated as a percentage of the total cell number. Exposure (CIF alone, RSV alone, ATRA alone, $\mathrm{CIF}+\mathrm{RSV}$ or CIF+ATRA) versus vehicle control, ${ }^{*} \mathrm{P}<0.05$ and ${ }^{* * * *} \mathrm{P}<0.001$ vs. vehicle control. ${ }^{\# \#} \mathrm{P}<0.01$ and ${ }^{\# \# \#} \mathrm{P}<0.001$ vs. CIF alone. ${ }^{\wedge} \mathrm{P}<0.01$ vs. RSV or ATRA alone. CIF, clofarabine; RSV, resveratrol; ATRA, all-trans retinoic acid.

domain of PCNA. Thus, CDKN1A polypeptide may disturb the formation of PCNA-DNMT1 complex, and then leads to repression of DNA methylation processes (41). The estimation of CDKN1A expression on mRNA level (in connection and comparison with DNMT1 expression) allows defining the potential interrelations between DNA methylation processes and expression of DNMT1 and CDKNIA genes in cells exposed to natural bioactive compounds and CIF, also in combined therapy. So we found that changes in DNMT1 expression are associated with concomitant changes in CDKN1A mRNA level (Fig. 3D and E). Upon 72 h-incubation of K562 cells with ATRA at $\mathrm{GI}_{50}$ concentration, $C D K N 1 A$ transcript level increased almost three times, and almost two times in cells exposed to $\mathrm{GI}_{50}$ concentration of RSV (Fig. 3E), in comparison to control unexposed cells. Since ATRA binds to nuclear RARs that heterodimerize with RXRs, it may further modulate transcription through cognate response elements in the promoters of the target genes including CDKN1A $(42,43)$. Due to structural similarity of RSV to estradiol and its binding to estrogen receptors (ERs) it may elicit similar responses as upon endogenous estrogens and modulate the expression of estrogen-responsive genes, such as CDKN1A (44).

Combination of ATRA and CIF resulted in a 3.3-fold increase in $C D K N 1 A$ mRNA level. CIF used alone did not influence the $C D K N 1 A$ expression, and the combination of CIF+RSV did not increase the level of CDKN1A above that achieved with RSV used alone (Fig. 3E, upper panel). Our findings suggest that especially CIF+ATRA-mediated concomitant $C D K N 1 A$ induction and DNMT1 downregulation in K562 cells may decrease DNA methylation efficiency of TSGs.

According to Oncomine publicly available data in all types of leukemia, CDKN1A expression is significantly decreased as compared to normal blood cells (Fig. 3B). Thus, reactivation of CDKNIA gene encoding protein capable of cell cycle arrest is one of the goals of anti-leukemic therapy (45).

DNA methylation-mediated PTEN reactivation in $K 562$ cells exposed to CIF combined with RSV or ATRA. PTEN is a multifunctional tumor suppressor gene, encoding a phosphatase with dual specificity for lipid and protein substrates, has been shown to be silenced in multiple cancers, including different types of leukemia (Fig. 4A). The PTEN downregulation in cancer cells may be related to genetic changes, but also it may result from hypermethylation of its promoter region, which partly implies epigenetic regulation of PTEN transcription (46-48). DNA methylation-mediated regulation of PTEN expression was observed for example in ALL (46), breast cancer (47) and colorectal cancer (48).

Oncomine data indicate that PTEN is transcriptionally silenced in three types of leukemia, including ALL, CLL and AML (Fig. 4A). According to the results of one available study with CML patients, no significant difference in PTEN expression has been noticed between cancer and normal blood cells (Fig. 4A). The proximal promoter region including $\mathrm{CpG}$ island of PTEN has been depicted in Fig. 4C. According to publicly available Illumina 450K data (GSE106600), currently the only available study for CML patients, any significant changes 
A
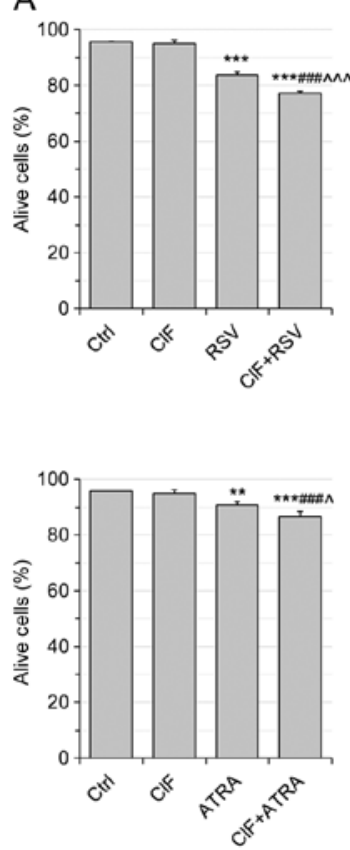

B
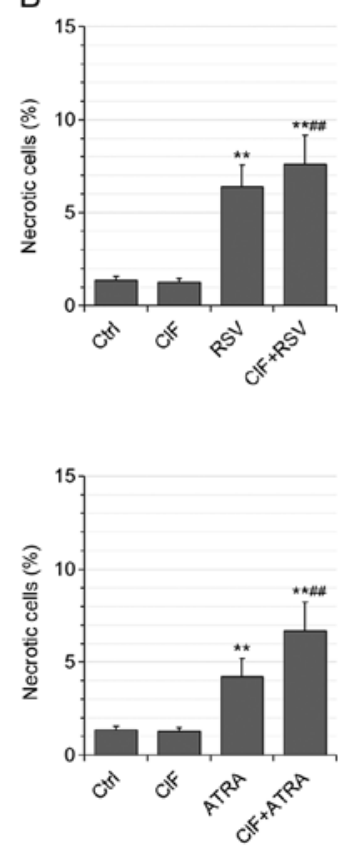

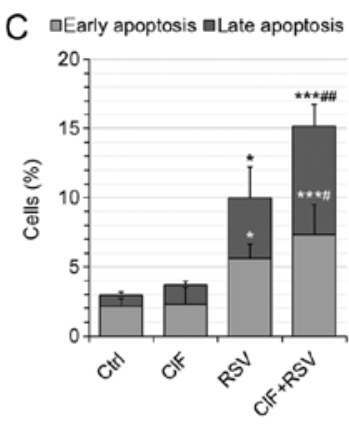

घEarly apoptosis Late apoptosis

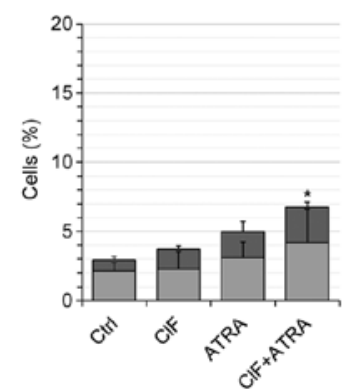

D
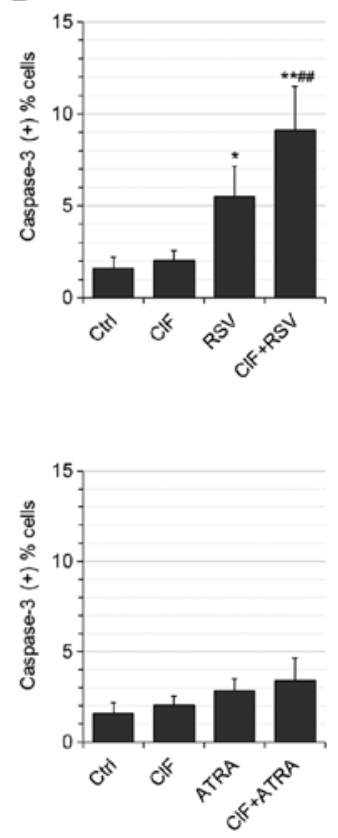

Figure 2. Effects of CIF, RSV and ATRA, as well as CIF in combination with RSV (upper panels) or ATRA (bottom panels), on the number of: (A) viable (Ann-/PI-), (B) necrotic (Ann-/PI+) cells, (C) early apoptotic (Ann+/PI-) and late apoptotic (Ann+/PI+) cells as well as on (D) caspase-3 activity in K562 cells. All the compounds were used at $\mathrm{GI}_{50}$ concentrations in all experiments. Data represent the mean $\pm \mathrm{SD}$ of three independent experiments. ${ }^{*} \mathrm{P}<0.05,{ }^{* * *} \mathrm{P}<0.01$ and ${ }^{* * *} \mathrm{P}<0.001$ vs. vehicle control; ${ }^{\# \#} \mathrm{P}<0.01$ and ${ }^{\# \# \#} \mathrm{P}<0.001$ vs. CIF alone; ${ }^{\wedge} \mathrm{P}<0.05$ and ${ }^{\wedge \wedge} \mathrm{P}<0.001$ vs. RSV or ATRA alone. CIF, clofarabine; RSV, resveratrol; ATRA, all-trans retinoic acid.

have not been observed in PTEN promoter methylation within CpGs covered on Illumina 450K microarray in CML cells as compared to normal blood cells (Fig. 4B). The detailed map in Fig. $4 \mathrm{C}$ shows the exact position of the tested $\mathrm{CpG}$ site, that is the $\mathrm{CpG}$ site within PTEN proximal promoter $\mathrm{CpG}$ island, i.e., 5'UTR and/or first exon (+973 bp from transcription start site, TSS), not covered on Illumina $450 \mathrm{~K}$ array (marked in black), located between two CpGs from this microarray platform, i.e., cg03588460 (+337 bp from TSS, marked in gray) and cg08859916 (+997 bp from TSS, marked in gray) (Fig. 4C). In our previous studies, this CpG (chr10: 89624078, according to Human GRCh37/hg19 Assembly) has been shown to be differentially methylated between breast cancer cell lines with different level of invasiveness, suggesting its regulatory role in PTEN transcription $(14,18,30)$. Putative transcription factor binding sites are demonstrated on the PTEN gene map (Fig. 4C), as predicted using TransFac. The multiple binding sites for DNA methylation-sensitive transcription factors within the tested PTEN promoter fragment support its potential regulatory role in PTEN transcription (Fig. 4C) $(18,47,48)$.

Previously, we identified the role of CIF in the regulation of promoter methylation and expression of PTEN in K562 (CML) cells (13). In the present study, we checked if RSV and ATRA used alone can also affect the transcriptional activity of these genes through the remodeling of their promoter methylation.

72-hour exposure of K562 cells to RSV used alone at $\mathrm{GI}_{50}=11.5 \mu \mathrm{M}$, and ATRA used alone at $\mathrm{GI}_{50}=30 \mu \mathrm{M}$ concentration led to significant decreases in PTEN promoter methylation by 51 and $24 \%$, respectively (Fig. 4D), comparing to control unexposed cells (63\%). CIF administrated alone mediated $7 \%$ diminution in PTEN promoter methylation level, although no significant changes in DNMT1 expression have been observed. Our initial unpublished studies in K562 cells indicate that CIF exposure leads to inhibition of the activity of two enzymes important for 2'-deoxyadenosine metabolism, deoxyadenosine deaminase (ADA) and S-adenosyl-L-homocysteine (SAH) hydrolase. CIF used at $5 \mathrm{nM}$ concentration caused decreases in ADA and SAH-hydrolase activities by 30 and $15 \%$, respectively. The CIF-mediated repression of ADA activity may lead to 2'-deoxyadenosine accumulation up to the level of toxic concentration in exposed cells. The raised levels of 2'-deoxyadenosine in cells can indirectly disrupt DNA methylation reaction via SAH-hydrolase inhibition leading to SAM pool depletion. A similar effect was shown by Wyczechowska and Fabianowska-Majewska (49) in K562 cells exposed to cladribine (49).

Upon exposure of K562 cells to CIF combined with ATRA, we observed almost complete demethylation of PTEN promoter compared to control K562 cells (Fig. 4D, bottom panel), whereas the extent of PTEN hypomethylation followed by CIF+RSV administration was similar to that caused by RSV alone (by approximately 50\%) (Fig. 4D, upper panel). These alterations in the PTEN methylation pattern in K562 cells were accompanied by enforced expression of this gene (Fig. 4E). The robust PTEN upregulation was detected after both combinatorial administrations, CIF+RSV or CIF+ATRA, that caused increases in PTEN transcript level by 59 and $44 \%$, when compared to control K562 cells, respectively (Fig. 4E). Surprisingly, although CIF and RSV used alone did not lead to any significant changes in PTEN expression in K562 cells upon $72 \mathrm{~h}$ of exposure, those compounds together exerted significant 59\% PTEN upregulation (Fig. 4E, bottom panel).

Possibly, different concentration of CIF and RSV used alone as well as other exposure time could benefit in stronger PTEN 
A DNMT1 expression (Oncomine)

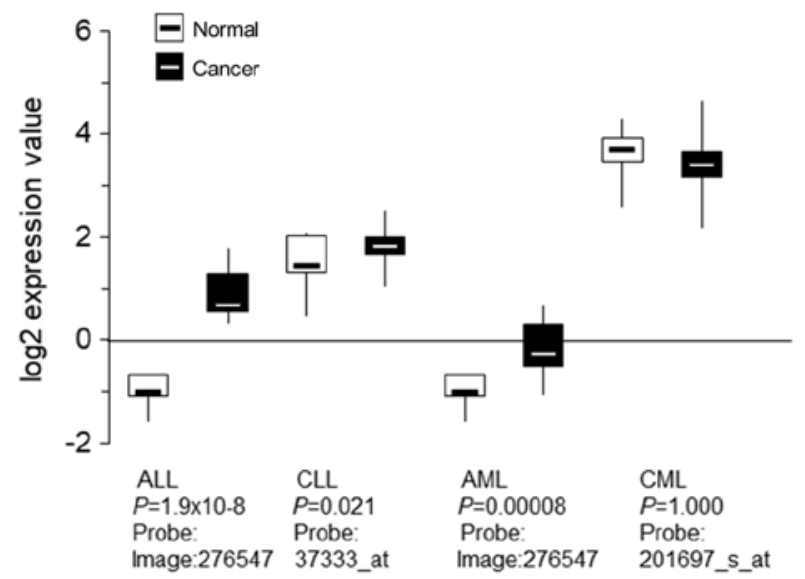

B CDKN1A expression (Oncomine)

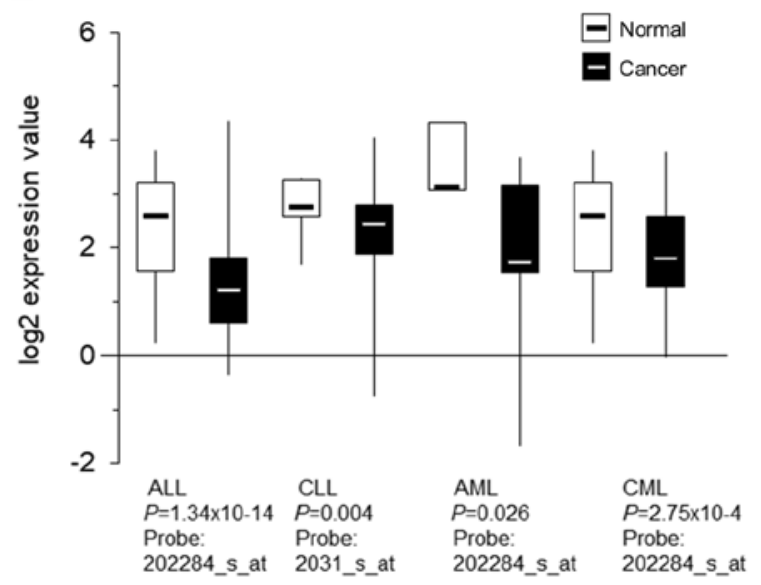

C DNMT1 protein level in K562 cells

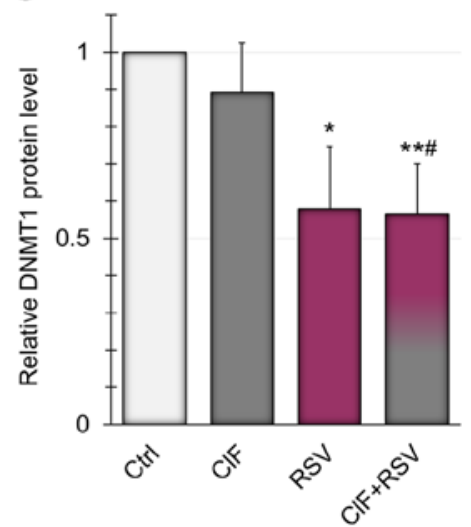

DNMT1 protein level in K562 cells

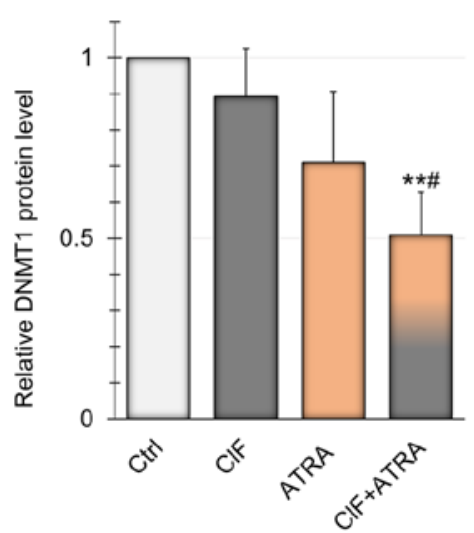

D DNMT1 expression in K562 cells

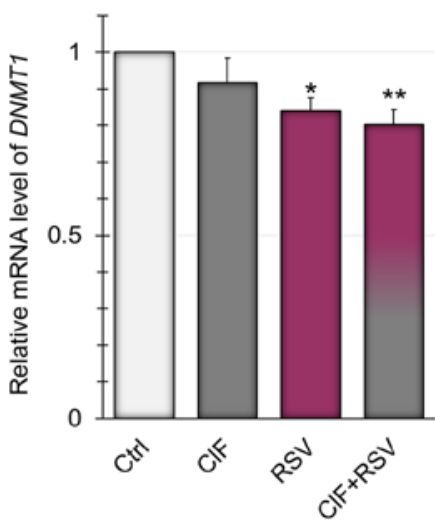

DNMT1 expression in K562 cells

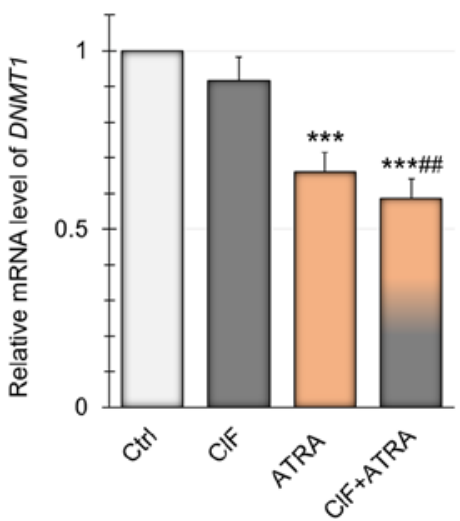

E CDKN1A expression in K562 cells

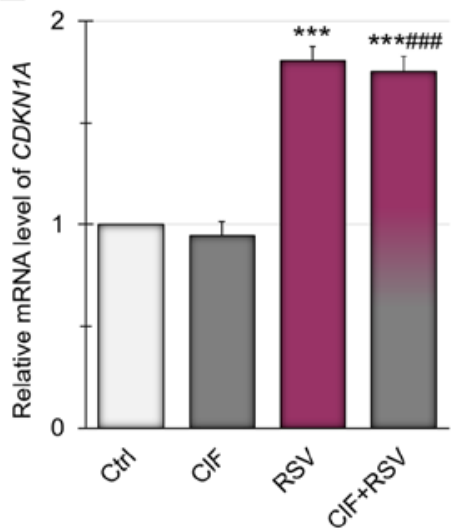

CDKN1A expression in K562 cells

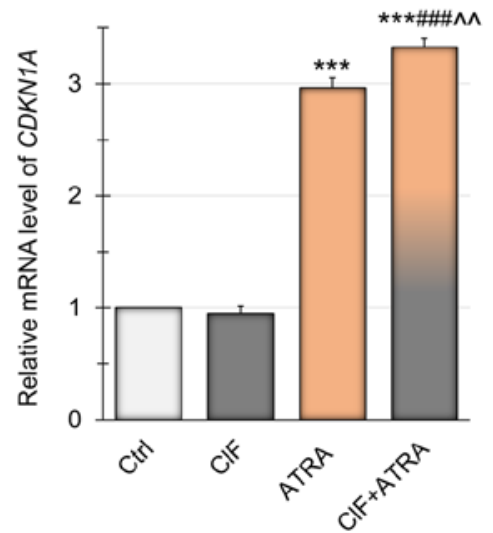

Figure 3. Expression of DNMT1 and CDKN1A genes in different types of leukemia and in K562 cells. (A) Gene expression microarray data for DNMT1 in different types of leukemia. The normal vs. cancer gene expression data were obtained from Oncomine and are presented as log2-transformed median centered per array, and SD-normalized to 1 per array. The presented changes are statistically significant $(\mathrm{P}<0.05)$ apart from the one for CML leukemia (lack of statistically significant data). (B) Gene expression microarray data for CDKN1A in different types of leukemia. The normal vs. cancer gene expression data were obtained from Oncomine and are presented as log2-transformed median centered per array, and SD-normalized to 1 per array. The presented changes are statistically significant $(\mathrm{P}<0.05)$. Effects of CIF, RSV and ATRA, as well as CIF in combination with RSV (upper panels) or ATRA (bottom panels) on:

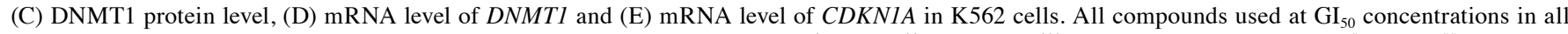
experiments. Data represent the mean $\pm \mathrm{SD}$ of three independent experiments. ${ }^{*} \mathrm{P}<0.05,{ }^{* * *} \mathrm{P}<0.01$ and ${ }^{* * * *} \mathrm{P}<0.001$ vs. vehicle control; ${ }^{\not} \mathrm{P}<0.05,{ }^{\# \# /} \mathrm{P}<0.01$ and

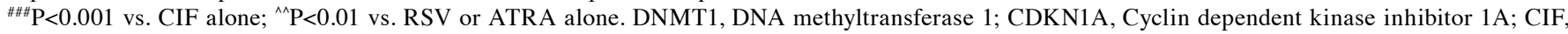
clofarabine; RSV, resveratrol; ATRA, all-trans retinoic acid; SD, standard deviation.

re-expression (13). It may also suggest that these compounds may cooperate in other unknown mechanisms driving changes in PTEN expression.
Our findings suggest partial involvement of DNA methylation in the regulation of $P T E N$ transcriptional activity, although other mechanisms can play an additional role as well (46-48). 


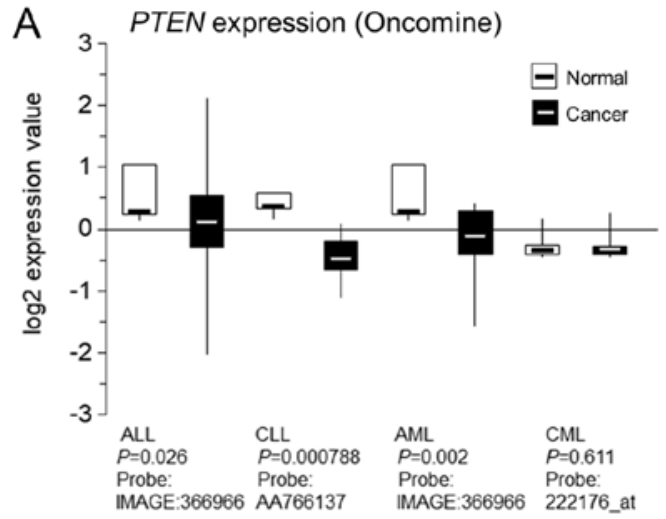

C PTEN

CpG: 5'UTR, 1'texon_CpG island

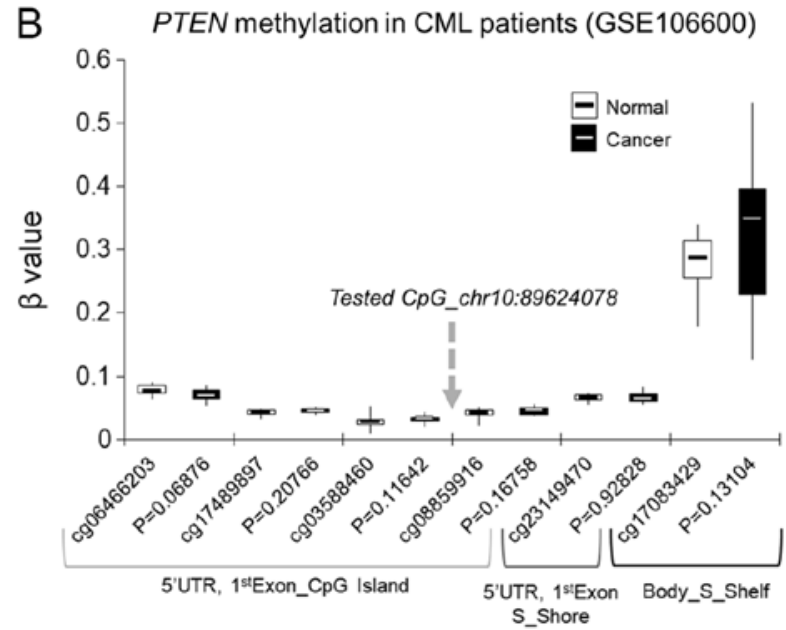

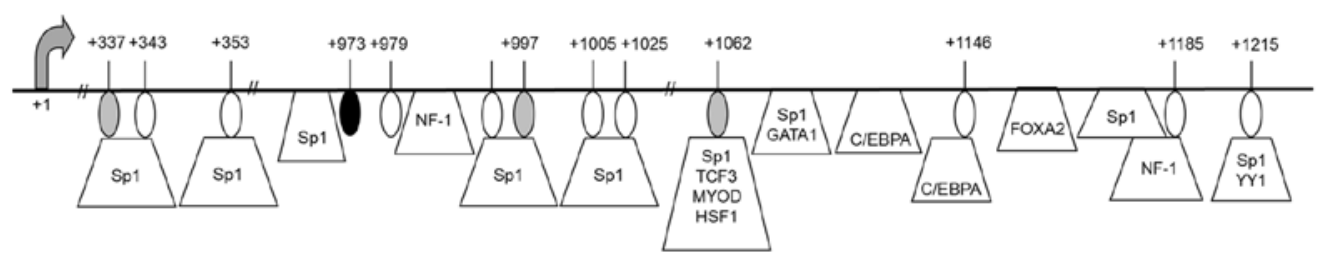

$\mathrm{CPG}$ island

D

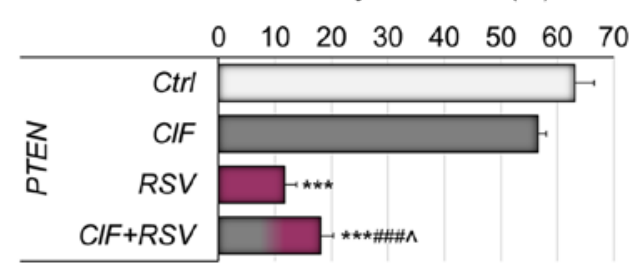

Methylation level (\%)

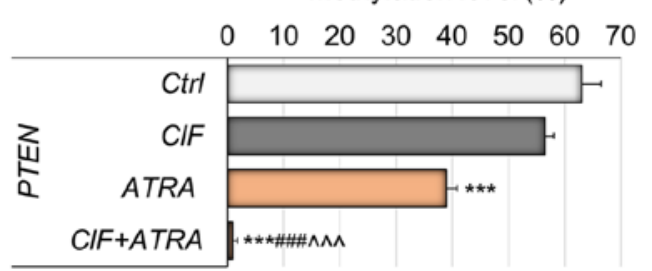

$E$
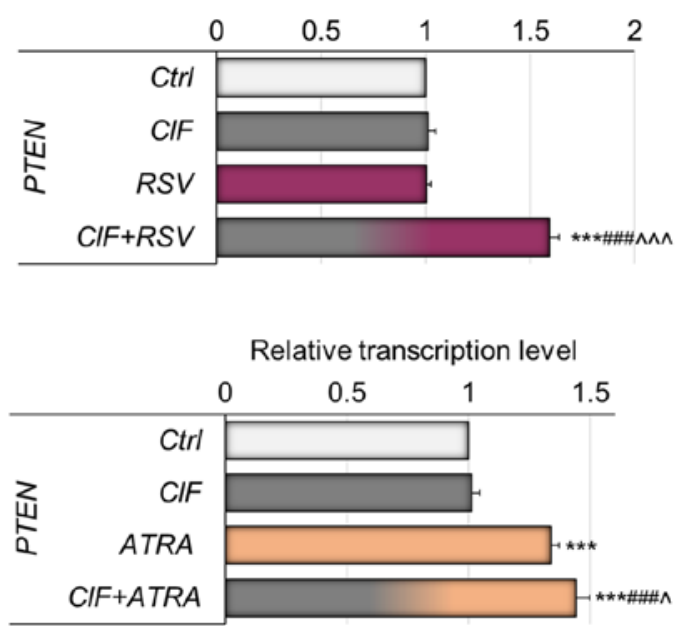

Figure 4. Relevance of DNA methylation-mediated silencing of PTEN in human leukemia in vivo. (A) Gene expression microarray data for PTEN in different types of leukemia. The normal vs. cancer gene expression data were obtained from Oncomine and are presented as $\log 2$-transformed median centered per array, and SD-normalized to 1 per array. The presented changes are statistically significant $(\mathrm{P}<0.05)$ apart from the one for CML leukemia (lack of statistically significant data). (B) Methylation status of the $\mathrm{CpG}$ sites located in the neighborhood of CpG site tested by MSRA (marked with gray arrow) within PTEN CpG island, covered on Illumina 450K array and expressed as beta value in CML and normal blood cells, based on NCBI's Gene Expression Omnibus GEO (publicly available datasets, no. GSE106600). Beta value, the methylation score for a specific $\mathrm{CpG}$ site according to the fluorescent intensity ratio with any values between 0 (unmethylated) and 1 (completely methylated). (C) A map of the PTEN CpG island within gene first exon (Human GRCh37/hg19 Assembly). The CpG site [+973 bp from transcription start site (TSS)], which methylation state was tested by MSRA, is indicated by a black oval shape. The CpG sites located nearby, covered on Illumina $450 \mathrm{~K}$ microarray platform, are depicted by gray ovals. Putative transcription factor binding sites are marked as predicted using TransFac. Effects of CIF, RSV and ATRA, as well as CIF in combination with RSV (upper panels) or ATRA (bottom panels) on (D) methylation of $P T E N$ proximal promoter, and (E) expression on mRNA level of PTEN gene in K562 cells (72 h exposure). All compounds used at $\mathrm{GI}_{50}$ concentrations in all experiments. Data represent the mean $\pm \mathrm{SD}$ of three independent experiments. ${ }^{* * *} \mathrm{P}<0.001$ vs. vehicle control; ${ }^{\# \# \#} \mathrm{P}<0.001$ vs. CIF alone; ${ }^{\wedge} \mathrm{P}<0.05$ and ${ }^{\wedge \wedge}{ }^{\wedge} \mathrm{P}<0.001$ vs. RSV or ATRA alone. PTEN, phosphatase and tensin homologue; SD, standard deviation.

RARB transcriptional reactivation followed by combinatorial exposures in $K 562$ cells partly related to its promoter hypomethylation. Expression of some tumor suppressor genes might be indirectly regulated by PTEN, one of them is
RARB. Lefebvre et al (50) reported that PTEN via negative regulation of PI $3 \mathrm{~K} / \mathrm{AKT}$ signaling pathway could affect $R A R B$ expression by blocking of SMRT co-repressor recruitment to $R A R B$ promoter region, which enhances histone acetylation 
A RARB expression (Oncomine)

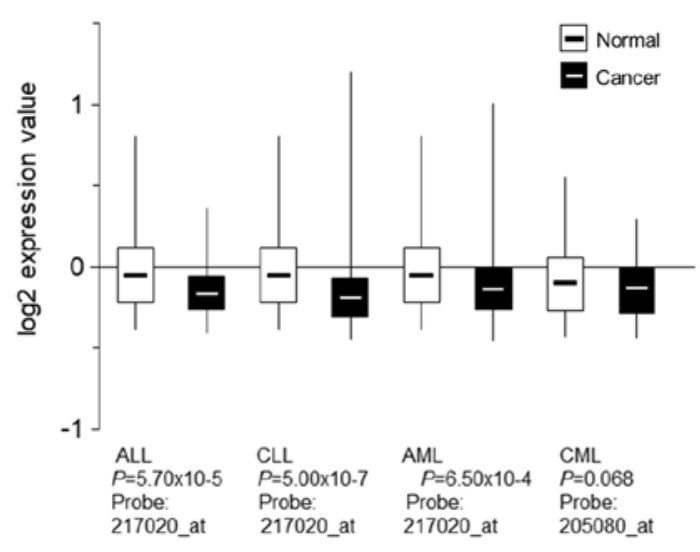

C

RARB

$\mathrm{CpG}: \mathrm{TSS} 200$, Enhancer

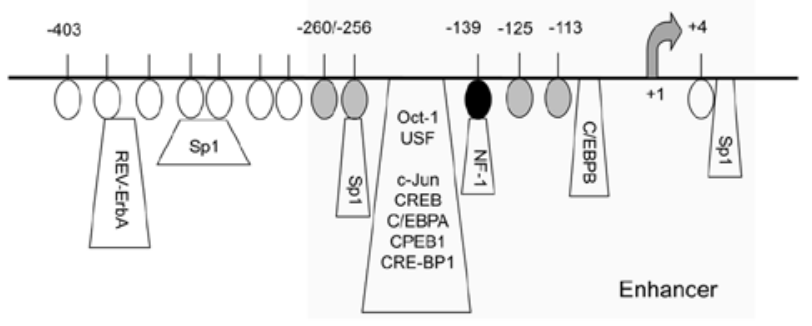

E

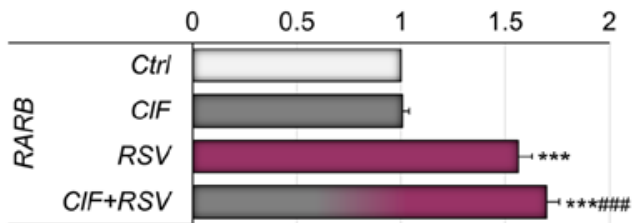

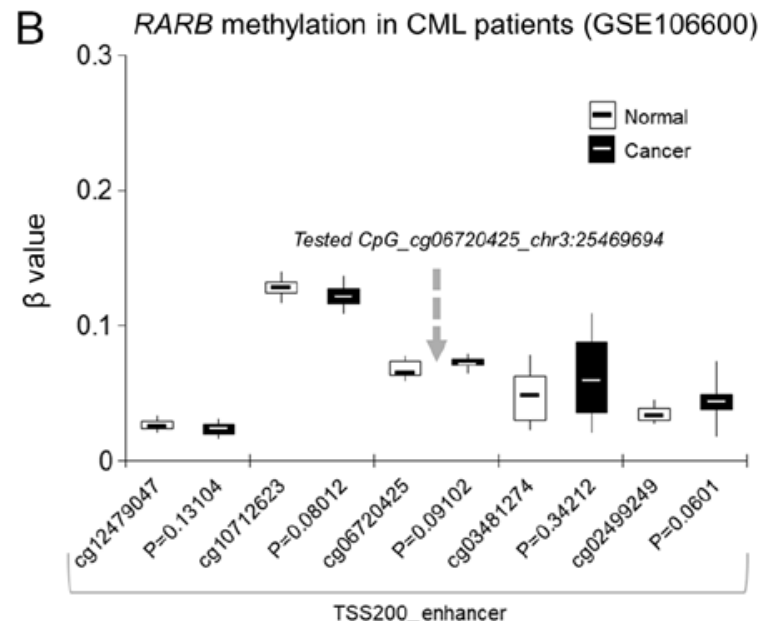

D
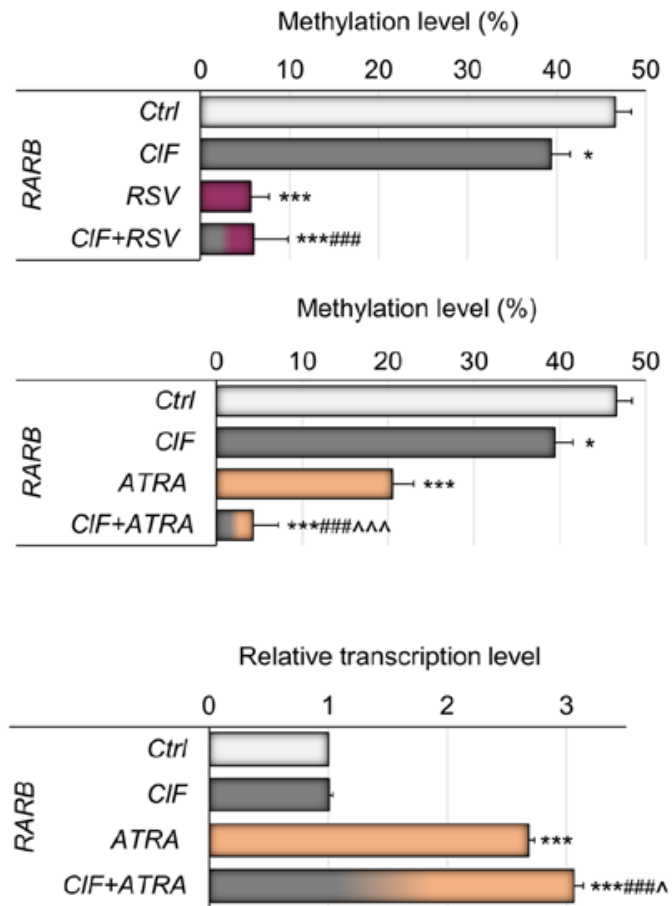

Figure 5. Relevance of DNA methylation-mediated silencing of $R A R B$ in human leukemia in vivo. (A) Gene expression microarray data for $R A R B$ in different types of leukemia. The normal vs. cancer gene expression data were obtained from Oncomine and are presented as $\log 2$-transformed median centered per array, and SD-normalized to 1 per array. The presented changes are statistically significant $(\mathrm{P}<0.05)$ apart from the one for $\mathrm{CML}$ leukemia $(\mathrm{P}=0.068)$. (B) Methylation status of the CpG sites located in the neighborhood of CpG site tested by MSRA (marked with gray arrow) covered on Illumina 450K array and expressed as beta value in CML and normal blood cells, based on NCBI's Gene Expression Omnibus GEO (publicly available datasets, no. GSE106600). Beta value, the methylation score for a specific $\mathrm{CpG}$ site according to the fluorescent intensity ratio with any values between 0 (unmethylated) and 1 (completely methylated). (C) A map of the RARB enhancer within TSS200 promoter region (Human GRCh37/hg19 Assembly). The CpG site [-139 bp from transcription start site (TSS)], which methylation state was tested by MSRA, is indicated by a black oval shape. The CpG sites located nearby, covered on Illumina 450K microarray platform, are depicted by gray ovals. Putative transcription factor binding sites are marked as predicted using TransFac. The effects of CIF, RSV and ATRA used alone, as well as CIF in combination with RSV or ATRA on (D) methylation of RARB promoter, and (E) expression on mRNA level of RARB gene in K562 cells. All compounds used at $\mathrm{GI}_{50}$ concentrations in all experiments. Data represent the mean $\pm \mathrm{SD}$ of three independent experiments. "P<0.05 and ${ }^{* * *} \mathrm{P}<0.001$ vs. vehicle control; ${ }^{\# \# \#} \mathrm{P}<0.001$ vs. CIF alone; ${ }^{\wedge} \mathrm{P}<0.05$ and ${ }^{\wedge \wedge} \mathrm{P}<0.001$ vs. RSV or ATRA alone. RARB, retinoic acid receptor beta; SD, standard deviation; CIF, clofarabine; RSV, resveratrol; ATRA, all-trans retinoic acid.

and promotes $R A R B$ transcription (50). Moreover, according to publicly available data (Oncomine), tumor suppressor gene $R A R B$ is downregulated in all types of leukemia (Fig. 5A). In Fig. 5B, the methylation status of CpG sites at TSS200 promoter region of $R A R B$ enhancer in CML and healthy individuals has been depicted (analyzed by Illumina 450K Human Methylation Array, publicly available datasets from NCBI's Gene Expression Omnibus GEO no. GSE106600). Among the
$5 \mathrm{CpG}$ sites within the demonstrated fragment of the $R A R B$ promoter, the CpG site located -139 bp from TSS, cg06720425 (chr3:25469694, Human GRCh37/hg19 Assembly) was examined by MSRA (Fig. 5C). Similarly to PTEN, the methylation state of the tested RARB CpG site has been shown to distinguish between non-invasive and highly invasive breast cancer cell lines, implying its potential regulatory role in $R A R B$ transcription (14). 


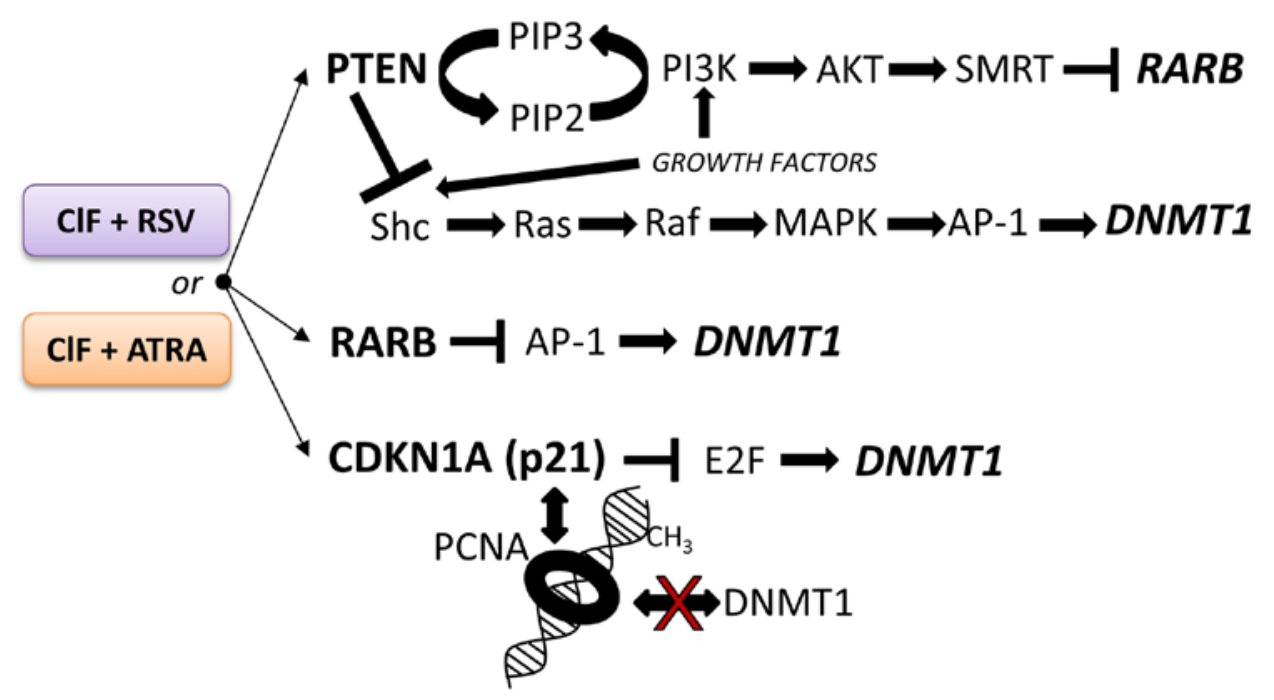

Figure 6. The potential repressive effects of the tested combinatorial exposures of CIF with RSV or ATRA on modulation of DNMT1 transcription and/or DNMT1 activity in K562 leukemia cells. Implications of PTEN-mediated negative regulation of intracellular oncogenic signaling pathways, including $\mathrm{PI} 3 \mathrm{~K} / \mathrm{AKT}$ and MAPK/AP-1. RARB and 21 (CDKN1A) proteins are negative regulators of AP-1 and E2F. These transcription factors (AP-1 and E2F) activate $D N M T 1$ expression due to the presence of binding sites in DNMT1 regulatory region. A competition of CDKN1A (p21) with DNMT1 for the same binding site on proliferating cell nuclear antigen. Shc, SH2-containing collagen-related proteins; PIP2, phosphatidylinositol (4,5)-bisphosphate; PIP3, phosphatidylinositol (3,4,5)-trisphosphate; SMRT, thyroid-, retinoic-acid-receptor-associated corepressor. CIF, clofarabine; DNMT1, DNA methyltransferase 1; RSV, resveratrol; ATRA, all-trans retinoic acid; PTEN, phosphatase and tensin homologue; CDKN1A, Cyclin dependent kinase inhibitor 1A.

In K562 cells exposed to CIF, RSV or ATRA, used alone, as well as to CIF+RSV and CIF+ATRA, statistically significant demethylation of $R A R B$ gene promoter was observed. CIF reduced the RARB promoter methylation level by approximately $10 \%$ in comparison to control cells, RSV by $41 \%$ and ATRA by $26 \%$ (Fig. 5D). Combinational treatment with CIF+ATRA caused almost total demethylation of $R A R B$ promoter with concomitant over 3 -fold increase in gene expression (Fig. 5D and E, bottom panels). Interestingly, the exposure to RSV and CIF+RSV, despite robust alteration in promoter methylation led to less pronounced $R A R B$ up-regulation, by 60-70\% (Fig 5D and E, upper panels).

It is worth pointing out, that the higher extent of changes mediated by CIF+ATRA combination in exposed K562 cells, i.e., $C D K N 1 A$ transcriptional reactivation that may result in decreased E2F activity, as well as re-expression of PTEN and $R A R B$ encoding proteins that inhibit AP-1 activity, strongly support enhanced DNMTI downregulation (Fig. 6) observed upon this combined exposure as compared to the compounds used alone and CIF+RSV combination (Figs. 3, 4 and 5). Mechanisms underlying the observed effects are interesting and remain to be elucidated in future experiments.

As some authors suggest, CML is the 'poster child' for targeted cancer therapy. The identified target, a product of abnormal gene BCR-ABL became the aim of drug development and as mentioned above the TKIs inhibitors were introduced to CML therapy. Nowadays the first- or second-generation TKIs are the first-line treatment of patients with newly diagnosed CML. Although initial responses are high, in more than $25 \%$ of patients the therapy fails and/or they develop resistance to the treatment. For several years, intensive work has been underway to explain treatment failure and to identify different mechanisms of the drug resistance. The resistance to TKIs based on clinical outcomes can be explained by genomic mechanisms (mutations in the BCR-ABL domain), but also by
BCR-ABL-independent mechanisms (poor compliance, drug influx and efflux, activation of alternative signaling pathways, plasma TKI concentration, insensitivity of quiescent stem cells) (51). However, epigenetic dysregulation of the expression of the CML-associated genes has been reported as well (7). Thus, in order to improve the effectiveness of CML therapies, there is a strong need to develop new treatment strategies.

Nishioka et al reported that hypermethylation of PTEN promoter is associated with this gene downregulation and activation of pro-survival signaling mediated by AKT in leukemia cells. According to the other authors' findings, the PTEN silencing induced by DNA methylation requires EZH2 and DNA methylation enzymes. Moreover, the authors claim that the epigenetic silencing of PTEN is one of the mechanisms that cause drug resistance in individuals with leukemia after exposure to Imatinib $(52,53)$. In this context demethylation and re-expression of PTEN seem to be a promising way to achieve long term therapeutic response. Our initial results show that natural bioactive compounds, mainly ATRA but also RSV, especially in combination with CIF, might positively modulate PTEN expression. Additionally, a combination of RSV with CIF indicates high pro-apoptotic activity in K562 CML cells. In work of Can et al (54) RSV (used alone in high dose) has also effectively induced apoptosis of K562/IMA-3 cells (resistant CML cells). These results may suggest the potential use of ATRA and/or RSV in CML therapy not only in patients with primary but also with acquired resistance to TKIs.

In summary, our study is the first to demonstrate the epigenetic anticancer capacity of the combinatorial exposures of CIF and ATRA or RSV in CML cells. Upon $72 \mathrm{~h}$-treatment, the tested combinations led to significant cell growth inhibition and greater induction of caspase-3-dependent apoptosis. These observations may be related to accompanied relevant DNMT1 downregulation and robust CDKNIA upregulation, with a concomitant, enhanced decrease in DNMT1 protein 
level, especially after CIF with ATRA. Concurrent methylation-mediated $R A R B$ and $P T E N$ reactivation have been detected. The proteins encoded by these genes are crucial for the regulation of important intracellular oncogenic signaling pathways, including PI3K/AKT and MAPK/AP-1 pathways. Taken together, our results reveal that CIF used in combination with the tested phytochemicals, RSV or ATRA, has the higher ability to remodel DNA methylation marks and promote cell death in CML cells.

Future studies will focus on assessing the efficacy of clofarabine-phytochemical combination exposures in other CML in vitro and in vivo models. We believe that further extensive studies of this new combinatorial strategy, the CIF combinations with ATRA or RSV, may support its translational application as a therapeutic epigenetic approach against CML.

\section{Acknowledgements}

The authors would like to thank Dr Justyna Jakubowska from The Department of Pediatrics, Oncology and Hematology, as well as Professor Piotr Smolewski and Dr Barbara Cebula-Obrzut from Department of Experimental Hematology, Medical University of Lodz, Poland, for their support in performing and analyzing flow cytometry experiments.

\section{Funding}

This study was supported by Medical University of Lodz in Poland (grant nos. 503/6-099-01/503-61-001, 502-03/6-099-01/502-64-007, 502-03/6-099-01/502-64-089 and 502-03/6-099-01/502-64-133) granted to The Department of Biomedical Chemistry, Faculty of Health Sciences at the Medical University of Lodz (Lodz, Poland).

\section{Availability of data and materials}

All data generated or analyzed during this study are included in this published article.

\section{Authors' contributions}

AKS and KM conducted the experiments. AKS, KM, ASM, KFM and KL performed the analysis and contributed to writing and editing the manuscript. All authors read and approved the manuscript and agree to be accountable for all aspects of the research in ensuring that the accuracy or integrity of any part of the work are appropriately investigated and resolved.

\section{Ethics approval and consent to participate}

Not applicable.

\section{Patient consent for publication}

Not applicable.

\section{Competing interests}

The authors declare that they have no competing interests.

\section{References}

1. Chen Y, Peng C, Li D and Li S: Molecular and cellular bases of chronic myeloid leukemia. Protein Cell 1: 124-132, 2010.

2. Soverini S, de Benedittis C, Mancini M and Martinelli G: Mutations in the BCR-ABL1 kinase domain and elsewhere in chronic myeloid leukemia. Clin Lymphoma Myeloma Leuk 15 (Suppl): S120-S128, 2015.

3. Druker BJ, Talpaz M, Resta DJ, Peng B, Buchdunger E, Ford JM Lydon NB, Kantarjian H, Capdeville R, Ohno-Jones S and Sawyers CL: Efficacy and safety of a specific inhibitor of the BCR-ABL tyrosine kinase in chronic myeloid leukemia. N Engl J Med 344: 1031-1037, 2001.

4. Bhatia R, Holtz M, Niu N, Gray R, Snyder DS, Sawyers CL, Arber DA, Slovak ML and Forman SJ: Persistence of malignant hematopoietic progenitors in chronic myelogenous leukemia patients in complete cytogenetic remission following imatinib mesylate treatment. Blood 101: 4701-4707, 2003.

5. Chomel JC, Bonnet ML, Sorel N, Bertrand A, Meunier MC, Fichelson S, Melkus M, Bennaceur-Griscelli A, Guilhot F and Turhan AG: Leukemic stem cell persistence in chronic myeloid leukemia patients with sustained undetectable molecular residual disease. Blood 118: 3657-3660, 2011

6. Leo E and Martinelli G: DNA methylation in chronic myeloid leukemia. J Mol Genet Med 8: 118, 2014.

7. Koschmieder S and Vetrie D: Epigenetic dysregulation in chronic myeloid leukaemia: A myriad of mechanisms and therapeutic options. Semin Cancer Biol 51: 180-197, 2018.

8. Robertson KD: Epigenetic mechanisms of gene regulation. In: DNA Methylation and Cancer Therapy. Medical Intelligence Unit. Springer, Boston, MA, pp13-30, 2005.

9. Jaenisch R and Bird A: Epigenetic regulation of gene expression: How the genome integrates intrinsic and environmental signals. Nat Genet 33 (Suppl): S245-S254, 2003.

10. Jones PA and Baylin SB: The epigenomics of cancer. Cell 128: 683-692, 2007.

11. Chik F, Szyf M and Rabbani SA: Role of epigenetics in cancer initiation and progression. Adv Exp Med Biol 720: 91-104, 2011.

12. Chen T and Li E: Structure and function of eukaryotic DNA methyltransferases. Curr Top Dev Biol 60: 55-89, 2004.

13. Majda K, Kaufman-Szymczyk A, Lubecka-Pietruszewska K, Bednarek A and Fabianowska-Majewska K: Influence of clofarabine on transcriptional activity of PTEN, APC, RARB2, ZAP70 genes in K562 cells. Anticancer Res 30: 4601-4606, 2010.

14. Lubecka-Pietruszewska K, Kaufman-Szymczyk A, Stefanska B, Cebula-Obrzut B, Smolewski P and Fabianowska-Majewska K: Clofarabine, a novel adenosine analogue, reactivates DNA methylation-silenced tumour suppressor genes and inhibits cell growth in breast cancer cells. Eur J Pharmacol 723: 276-287, 2014.

15. Ghanem H Jabbour E, Faderl S, Ghandhi V, Plunkett W and Kantarjian H: Clofarabine in leukemia. Expert Rev Hematol 3: 15-22, 2010.

16. Ghanem H, Kantarjian H, Ohanian M and Jabbour E: The role of clofarabine in acute myeloid leukemia. Leuk Lymphoma 54: 688-698, 2013.

17. Stefanska B, Karlic H, Varga F, Fabianowska-Majewska $K$ and Haslberger A: Epigenetic mechanisms in anti-cancer actions of bioactive food components-the implications in cancer prevention. Br J Pharmacol 167: 279-297, 2012.

18. Stefanska B, Salamé P, Bednarek A and Fabianowska-Majewska K: Comparative effects of retinoic acid, vitamin D and resveratrol alone and in combination with adenosine analogues on methylation and expression of phosphatase and tensin homologue tumour suppressor gene in breast cancer cells. Br J Nutr 107: 781-790, 2012.

19. Lubecka K, Kurzava L, Flower K, Buvala H, Zhang H, Teegarden D, Camarillo I, Suderman M, Kuang S, Andrisani O, et al: Stilbenoids remodel the DNA methylation patterns in breast cancer cells and inhibit oncogenic NOTCH signaling through epigenetic regulation of MAML2 transcriptional activity. Carcinogenesis 37: 656-668, 2016.

20. Lee YJ, Lee YJ, Im JH, Won SY, Kim YB, Cho MK, Nam HS, Choi YJ and Lee SH: Synergistic anti-cancer effects of resveratrol and chemotherapeutic agent clofarabine against human malignant mesothelioma MSTO-211H cells. Food Chem Toxicol 52: 61-68, 2013.

21. Lee YJ, Hwang IS, Lee YJ, Lee CH, Kim SH, Nam HS, Choi YJ and Lee SH: Knockdown of Bcl-xL enhances growth-inhibiting and apoptosis-inducing effects of resveratrol and clofarabine in malignant mesothelioma H-2452 cells. J Korean Med Sci 29: 1464-1472, 2014. 
22. Lee YJ, Lee YJ and Lee SH: Resveratrol and clofarabine induces a preferential apoptosis-activating effect on malignant mesothelioma cells by Mcl-1 down-regulation and caspase-3 activation. BMB Rep 48: 166-171, 2015.

23. Kulkarni SS and Cantó C: The molecular targets of resveratrol. Biochim Biophys Acta 1852: 1114-1123, 2015.

24. Theodosiou M, Laudet V and Schubert M: From carrot to clinic: An overview of the retinoic acid signaling pathway. Cell Mol Life Sci 67: 1423-1445, 2010.

25. Tang XH and Gudas LJ: Retinoids, retinoic acid receptors, and cancer. Annu Rev Pathol 6: 345-364, 2011.

26. Connolly R, Nguyen NK and Sukumar S: Molecular pathways: Current role and future directions of the retinoic acid pathway in cancer prevention and treatment. Clin Cancer Res 19: 1651-1659, 2013.

27. Schenk T, Stengel S and Zelent A: Unlocking the potential of retinoic acid in anticancer therapy. Br J Cancer 111: 2039-2045, 2014.

28. Zhang W and Xu J: DNA methyltransferases and their roles in tumorigenesis. Biomark Res 5: 1, 2017.

29. $\mathrm{Wu} \mathrm{Q}$, Chen $\mathrm{ZM}$ and $\mathrm{Su} \mathrm{WJ}$ : Anticancer effect of retinoic acid via AP-1 activity repression is mediated by retinoic acid receptor alpha and beta in gastric cancer cells. Int J Biochem Cell Biol 34 1102-1114, 2002.

30. Stefanska B, Rudnicka K, Bednarek A and FabianowskaMajewska K: Hypomethylation and induction of retinoic acid receptor beta 2 by concurrent action of adenosine analogues and natural compounds in breast cancer cells. Eur J Pharmacol 638: 47-53, 2010.

31. McCabe MT, Davis JN and Day ML: Regulation of DNA methyltransferase 1 by the $\mathrm{pRb} / \mathrm{E} 2 \mathrm{~F} 1$ pathway. Cancer Res 65: 3624-3632, 2005.

32. Delavaine L and La Thangue NB: Control of E2F activity by p21Waf1/Cip1. Oncogene 18: 5381-5392, 1999.

33. Chuang LS, Ian HI, Koh TW, Ng HH, Xu G and Li BF: Human DNA-(cytosine-5) methyltransferase-PCNA complex as a target for p21WAF1. Science 277: 1996-2000, 1997.

34. Iida T, Suetake I, Tajima S, Morioka H, Ohta S, Obuse C and Tsurimoto T: PCNA clamp facilitates action of DNA cytosine methyltransferase 1 on hemimethylated DNA. Genes Cells 7: 997-1007, 2002.

35. Yamada KM and Araki M: Tumor suppressor PTEN: Modulator of cell signaling, growth, migration and apoptosis. J Cell Sci 114: $2375-2382,2001$

36. Iwase H, Omoto Y, Iwata H, Toyama T, Hara Y, Ando Y, Ito Y, Fujii Y and Kobayashi S: DNA methylation analysis at distal and proximal promoter regions of the oestrogen receptor gene in breast cancers. Br J Cancer 80: 1982-1986, 1999.

37. Pfaffl MW, Horgan GW and Dempfle L: Relative expression software tool (REST) for group-wise comparison and statistical analysis of relative expression results in real-time PCR. Nucleic Acids Res 30: e36, 2002.

38. Sui T, Ma L, Bai X, Li Q and Xu X: Resveratrol inhibits the phosphatidylinositide 3-kinase/protein kinase $\mathrm{B} / \mathrm{mammalian}$ target of rapamycin signaling pathway in the human chronic myeloid leukemia K562 cell line. Oncol Lett 7: 2093-2098, 2014.

39. Wang B, Liu J and Gong Z: Resveratrol induces apoptosis in K562 cells via the regulation of mitochondrial signaling pathways. Int J Clin Exp Med 8: 16926-16933, 2015.

40. Mizuno S, Chijiwa T, Okamura T, Akashi K, Fukumaki Y, Niho Y and Sasaki H: Expression of DNA methyltransferases DNMT1, 3A, and 3B in normal hematopoiesis and in acute and chronic myelogenous leukemia. Blood 97: 1172-1179, 2001.
41. Tan $\mathrm{HH}$ and Porter AG: p21(WAF1) negatively regulates DNMT1 expression in mammalian cells. Biochem Biophys Res Commun 382: 171-176, 2009.

42. Liu M, Iavarone A and Freedman LP: Transcriptional activation of the human p21(WAF1/CIP1) gene by retinoic acid receptor. Correlation with retinoid induction of U937 cell differentiation. J Biol Chem 271: 31723-31728, 1996.

43. Yu Z, Li W, Lu Q, Wang L, Zhang X, Han P, Chen P and Pei Y: p21 is required for atRA-mediated growth inhibition of MEPM cells, which involves RAR. J Cell Biochem 104: 2185-2192, 2008.

44. Bowers JL, Tyulmenkov VV, Jernigan SC and Klinge CM: Resveratrol acts as a mixed agonist/antagonist for estrogen receptors alpha and beta. Endocrinology 141: 3657-3667, 2000.

45. Parveen A, Akash MS, Rehman K and Kyunn WW: Dual role of p21 in the progression of cancer and its treatment. Crit Rev Eukaryot Gene Expr 26: 49-62, 2016.

46. Montiel-Duarte C, Cordeu L, Agirre X, Román-Gómez J, Jiménez-Velasco A, José-Eneriz ES, Gárate L, Andreu EJ, Calasanz MJ, Heiniger A, et al: Resistance to Imatinib mesylate-induced apoptosis in acute lymphoblastic leukemia is associated with PTEN down-regulation due to promoter hypermethylation. Leuk Res 32: 709-716, 2008.

47. García JM, Silva J, Peña C, Garcia V, Rodríguez R, Cruz MA, Cantos B, Provencio M, España P and Bonilla F: Promoter methylation of the PTEN gene is a common molecular change in breast cancer. Genes Chromosomes Cancer 41: 117-124, 2004.

48. Goel A, Arnold CN, Niedzwiecki D, Carethers JM, Dowell JM, Wasserman L, Compton C, Mayer RJ, Bertagnolli MM and Boland CR: Frequent inactivation of PTEN by promoter hypermethylation in microsatellite instability-high sporadic colorectal cancers. Cancer Res 64: 3014-3021, 2004.

49. Wyczechowska D and Fabianowska-Majewska K: The effects of cladribine and fludarabine on DNA methylation in K562 cells. Biochem. Pharmacol 65: 219-225, 2003.

50. Lefebvre B, Brand C, Flajollet S and Lefebvre P: Down-regulation of the tumour suppressor gene retinoic acid receptor beta2 through the phosphoinositide 3-knase/Akt signaling pathway. Mol Endocrinol 20: 2109-2121, 2006.

51. Lussana F, Intermesoli T, Stefanoni P and Rambaldi A: Mechanisms of resistance to targeted therapies in chronic myeloid leukemia. Handb Exp Pharmacol 249: 231-250, 2018.

52. Nishioka C, Ikezoe T, Yang J and Yokoyama A: Long-term exposure of leukemia cells to multi-targeted tyrosine kinase inhibitor induces activations of AKT, ERK and STAT5 signaling via epigenetic silencing of the PTEN gene. Leukemia 24: 1631-1640, 2010.

53. Nishioka C, Ikezoe T, Yang J, Udaka K and Yokoyama A: Imatinib causes epigenetic alterations of PTEN gene via upregulation of DNA methyltransferases and polycomb group proteins. Blood Cancer J 1: e48, 2011.

54. Can G, Cakir Z, Kartal M, Gunduz U and Baran Y: Apoptotic effects of resveratrol, a grape polyphenol, on imatinib-sensitive and resistant K562 chronic myeloid leukemia cells. Anticancer Res 32: 2673-2678, 2012.

This work is licensed under a Creative Commons Attribution-NonCommercial-NoDerivatives 4.0 International (CC BY-NC-ND 4.0) License. 